\title{
Fuentes orales para una aproximación al exilio femenino en Colombia
}

\author{
maría Eugenia martínez Gorroño
}

\section{INTRODUCCIÓN}

En el trabajo de recopilación de datos, base para el estudio del exilio español en Colombia como consecuencia de la guerra civil, que llevo a cabo en la actualidad, forman parte fundamental las fuentes orales. Los protagonistas del mismo: adultos supervivientes, niños (en el momento del exilio) o simplemente hijos nacidos en el pais de acogida, son una fuente de información de valor insustituible; sin los cuales el trabajo de recuperación de datos sería de enorme dificultad y, en ocasiones, simplemente imposible.

Nos encontramos en un pais en el que sus circunstancias pasadas y actuales apenas permiten la consulta de fuentes documentales; la mayor parte de las veces inexistentes por los avatares y conmociones politicas que ha sufrido, como el llamado "bogotazo" de $1949^{1}$ en que se destruyeron e incendiaron un número importante de archivos de organismos oficiales; y quizás en algunos casos porque la circunstancia actual tampoco permite consultar archivos, por otra parte de dudosa existencia.

' Proceso revolucionario que después de muchos meses culminó el 9 de abril de 1949 con la muerte del lider popular Jorge Eleizer Gaitán. 
Las fuentes orales, por tanto, son imprescindibles. Los protagonistas, sus descendientes o compañeros de profesión, proporcionan no sólo el relato de las viviencias, el detalle del trabajo llevado a cabo, etc.; sino que, generalmente, constituyen la única fuente documental a la que se tiene acceso.

Junto al relato oral, la mayor parte de las veces, nos es ofrecida la posibilidad de consultar el archivo familiar, en el que encontraremos: publicaciones, datos bibliográficos, recortes de prensa, material gráfico, pasaportes, contratos de trabajo, etc. incluso diarios personales $y$ correspondencia.

Todo ello será una base para elaborar la historia de los acontecimientos, las vivencias y el trabajo de los protagonistas. A veces será la base cuya información pueda ser contrastada con la ofrecida por otras fuentes; en ocasiones, la mayor parte de las veces, la única. Por tanto, la fuente oral nos proporciona un testimonio relatado de unos hechos; $y$ esa misma fuente es la más idónea para ofrecernos otras nuevas fuentes o cauces de búsqueda en que se apoyen sus testimonios: los documentos de su archivo, el material en su poder, que confirma y apoya su relato.

Además, esta fuente oral está es disposición de abrirnos otros caminos en la búsqueda de información: lugares, centros de archivos, organismos, etc., relacionados con los protagonistas; que puedan ampliarnos, apoyarnos o complementarnos la información ya ofrecida por ella misma.

Igualmente, la fuente oral consultada, suele proporcionar el acceso a otra nueva fuente oral. Junto con el relato de las propias vivencias, va apareciendo el recuerdo de las personas que con ellos vivieron los mismos acontecimientos en circunstancias similares; que les mantuvieron próximos en los momentos del exilio; con los que compartieron viaje, llegada, ubicación, problemática o actividades.

De esta forma en los comienzos de la investigación, las fuentes orales aumentan en progresión geométrica: una persona entrevistada nos da acceso a otro cierto número de protagonistas; que consultados, cada uno de ellos, ofrecerá, generalmente, otras nuevas fuentes orales al historiador en búsqueda.

Asi la fuente oral es un cauce que el historiador abre, y una vez abierto fluye por si mismo. Siguiéndole proporciona la vía para cubrir la información, base para la reconstrucción de los hechos y las vivencias de los acontecimientos que trata de estudiar. 
En el caso concreto que estoy trabajando: el exilio español en Colombia; me encuentro con un tipo de "emigración" en la que los archivos del Consulado Oficial no pueden ser base documental, al menos en la búsqueda inicial. Los exiliados, contrarios por su misma condición al gobierno que está representando a su pais de origen, no reconocen esta representación, o simplemente temen las consecuencias de la inscripción legal en estos organismos oficiales. Por tanto, no acudirán a la Embajada Española ni al Consulado para cumplir los trámites de rigor, lógicos en cualquier otro tipo de emigración. Es preciso, pues, contactar con ellos de forma oral; a través de las fuentes orales, que se irán encadenando unas a otras.

La problemática en la búsqueda de información se complica hasta llegar a hacerse imposible, en los casos en que las fuentes orales son más dudosas o inexistentes. Así me ha venido sucediendo, casualmente, en el estudio de las mujeres exiliadas en Colombia. ¿Por qué se produce ésto en la búsqueda de datos sobre las exiliadas republicanas?

El estudio del exilio suele enfocarse intentando recabar datos a nivel profesional y cualitativo de los exiliados, y se realiza a partir de profesiones estructuradas y valoradas dentro de la sociedad pragmática en la que nos desenvolvemos y en donde la escala de valores no siempre se estructura desde la perspectiva de una visión humana y lógica.

Sería extraño, por ejemplo, hablar del trabajo cotidiano y las dificultades diarias motivadas por el exilio y la ubicación en un nuevo pais, con las que se enfrentó una madre con seis hijos como Montserrat Fargas Raymat (esposa a la sazón de Antonio Trías) cuya opinión personal con respecto a la oposición al régimen de Franco pudo ser dudosa (dada la trayectoria que su familia de origen mantuvo), y que ella misma relegó superponiendo, en cualquier caso, las ideas profundamente republicanas de su esposo ${ }^{2}$.

Quizás solo mencionáramos el nombre de Dominga Perpetua Sasiain para argumentar uno de los motivos fundamentales que llevaron a Andrés Perea Gallega (representante del Gobierno Vasco en Colombia) para elegir Colombia como lugar donde ubicar a la familia en el exilio; ya que habiéndose cuestionado la posibilidad de Australia y algunos otros países de habla inglesa, fue la razón del idioma y las dificultades que con respecto a este pudieran surgirle a su esposa, lo que parece que

${ }^{2}$ Según testimonio oral de su hijo Miguel Trías, en entrevista realizada en Bogotá en septiembre de 1988, conservada en el archivo personal de la autora. 
definitivamente llevó a la familia Perea-Sasiain a decidirse por su elección colombiana ${ }^{3}$.

Por tanto, estas mujeres y tantas otras, su labor e incluso sus nombres no figuran en los pequeños estudios que hasta ahora han aparecido sobre el exilio español republicano en Colombia; y quizás tampoco aparezca en el trabajo más profundo que al respecto me propongo llevar a cabo. Esta es una realidad que no podemos desconocer, aunque sin tener en cuenta.

Partiendo de ello, las mujeres estudiadas como exiliadas republicanas son aquellas que han llevado a cabo un trabajo profesional equiparado como tal en la sociedad del momento. Estas mujeres dedicadas a un cometido diferente del familiar, suelen ser mujeres solteras o sin hijos, dados también el contexto social y circunstancia femenina de los años treinta y cuarenta. La inexistencia por tanto de descendientes directos parece llevarnos a un paralelismo entre estas mujeres y la carencia de fuentes orales "de primera mano"; hecho que dificulta enormemente el trabajo en su caso, para la reconstrucción de sus historias de vida.

Este exilio de mujeres republicanas en Colombia debe ir encabezado, sin lugar a dudas, por las hemanas Rodrigo: María y Mercedes. Ellas eran solteras; por tanto la fuente oral que supone el descendiente directo es nulo en su caso. Esto complica en gran manera la labor de búsqueda de información sobre el trabajo que llevaron a cabo en el país, teniendo en cuenta que además, se vieron abocados, como un número importante de otros exiliados en Colombia, a una nueva emigración sobre los años cincuenta.

Las fuentes orales se reducen entonces a amigos e hijos de sus amigos que las conocieron. Pero estas fuentes orales («de segunda mano") no suele aportar datos profesionales claros o concretos $y$, por otra parte, no ofrecen, generalmente, ninguna información de tipo documental.

Circunstancia similar sucede en el caso de Manuela Manzanares, que aunque casada con José Francisco Cirre, la carencia de hijos de este matrimonio nos lleva a idénticas dificultades en la búsqueda de datos sobre su trabajo, y nos reitera la importancia de las fuentes orales para trabajos de esta índole.

${ }^{3}$ Dato ofrecido en entrevista oral mantenida con su hijo José Perea Sasiain en Bogotá en octubre de 1988, que se encuentra en el archivo personal de la autora. 
Citaremos igualmente en el presente trabajo a: M. ${ }^{a}$ Rosa Mallol Pibernat, en cuyo relato de vida es imprescindible la fuente oral de su esposo: José de Recasens; que he entrevistado en Bogotá en múltiples ocasiones, para recabar datos sobre su esposa, el padre de ésta, y gran número de exiliados más.

Completan el presente trabajo las historias de vida de: Genoveva Pons Rotger y de Lucia Garcia Villafranca.

En estos dos casos la fuente oral es la base de la reconstrucción que se lleva a cabo.

Genoveva Pons vive en Bogotá y la he entrevistado en varias ocasiones. Ella me ha facilitado un relato personal y gran cantidad de documentación que apoya y complementa aquél cuyas copias obras en mi archivo personal; así como un librito, titulado Tres años de antaño, de edición muy reducida; uno de cuyos ejemplares ha tenido la amabilidad de regalarme; en donde basándose en un diario que escribió durante el tiempo de su encarcelamiento, relata esta etapa de su vida.

Otras fuentes orales surgidas últimamente me llevaron a conocer y entrevistar en enero de este mismo año a $M .^{a}{ }^{a}$ Luz Velo, hija de la persona que encabeza la última parte del trabajo: Lucía García Villafranca; cuyo testimonio oral y algún material que me fue mostrado simultáneamente a la celebración de una larga entrevista que mantuvimos en su casa de Bogotá, son la única fuente de la reconstrucción que se ofrece.

\section{MUJERES ESPAÑOLAS EN COLOMBIA}

El exilio español en Colombia como consecuencia de la guerra civil es, cuantitativamente hablando, reducido (en comparación con el contigente numérico recibido por otros países iberoamericanos) pero en un nivel cualitativo, presenta gran importancia.

Colombia no fue un país totalmente abierto a este grupo de españoles. A pesar del apoyo del Presidente Eduardo Santos, ciertos grupos de la derecha colombiana se opusieron a la entrada de los «rojos" españoles, por lo que este neofascismo tropical consiguió hacer difícil la obtención del visado para Colombia. 
Los exiliados que consiguieron visado para este país correspondian en su mayoría a una clase social y profesional "culta". El visado de entrada fue dificil y se conseguía de forma más fácil por aquellas personas que pertenecian a dicha clase o fueron recomendadas por los recien llegados ya instalados.

Se trató de dar entradas a los «hombre de valia» bajo un concepto “meritocrático" ${ }^{4}$.

«A Colombia vinieron, gracias al Presidente Eduardo Santos, quien les tendió su mano generosa, profesionales y catedráticos altamente calificados y prestigiosos: médicos, ingenieros, matemáticos, químicos, botánicos, juristas, lingüistas, etc., que insuflaron a la Universidad un aliento vivificante y renovador. Si ellos encontraron aquí su segunda patria, fue porque España nos había dejado, a diferencia de las otras potencias conquistadoras y colonizadoras, muchas cosas de su propio solar» ${ }^{5}$.

En este grupo nos encontramos con algunas mujeres que trajeron, al igual que un número importante de varones, una trayectoria profesional prestigiada en España, y cuya labor, en la Colombia de los años cuarenta, significó una aportación de gran interés. Vinieron con el mismo espiritu que Garcia Banús manifestó en su Libro de Correspondencia, con: «mucho entusiasmo, buena voluntad, un poco de experiencia adquirida por mis ya demasiados años, con la ilusión de hacer en Colombia lo que por mi España hice en más de veinte años de sacrificios".

Las HERMANAS ROGRIGO, conocidas entre el grupo de exiliados con este nombre, llegaron a Colombia según datos consulares, en 1939, estableciéndose en Bogotá desde el principio.

María Rodrigo Bellido había nacido en Madrid el 20 de marzo de 1888 , y en los años de su exilio ya contaba con un "currículum» prestigioso en el mundo de la música. Excelente compositora, Maestra de Coros en El Real de Madrid, había estrenado ópera y zarzuelas como, por ejemplo: «Diana cazadora, opera de muerte al amor», con letra de los hermanos Quintero.

${ }^{4}$ ReCasens J. DE, "La emigración Española de 1939". Conterencia inaugural del ciclo "El exilio español en Colombia" celebrado en Bogotá del 17 de noviembre al 1 de diciem. bre de 1989.

${ }^{5}$ Osorio Osma, R., Historia de la Química en Colombia. Bogotá, Instituto Colombiano de Cultura Hispánica, diciembre de 1985, pág. 128. 
Llegó, como se ha dicho, a Colombia en 1939 en donde trabajó como docente en el "Gimnasio Moderno", colegio que, a imagen del "gimnasio" centro-europeo, se había creado en los años veinte y que gozaba de gran prestigio en Bogotá.

Igualmente fue profesora en la Escuela Normal Superior, entidad de carácter universitario, (digna de un estudio monográfico dentro del exilio español) creada por iniciativa liberal y que fue, para la Bogotá de los años cuarenta, la organización más progresista y de mayor prestigio, en donde se formó una élite de alumnos, que hoy están situados en primera línea de la política, las grandes empresas, los medios de difusión, las universidades, la investigación, etc. del país ${ }^{6}$. Es necesario apuntar que esta Escuela se creó con un amplísimo número de docentes españoles y del resto de Europa que conformaron una gran parte de su plantilla ${ }^{7}$.

María Rodrigo también fue profesora del Conservatorio Superior de Música, perteneciente a la Universidad Nacional de Colombia, en donde prestó sus servicios durante 10 años.

De personalidad simpática, afable y de buen carácter, mostraba especial sensibilidad por la música infantil. Dio clases a niños y puso música a poemas del prestigiado autor colombiano Rafael Pombo; resultado de ello, unas "Canciones Infantiles con acompañamiento de piano" de una calidad muy elevada.

Como concertista de piano e intérprete de notable categoria, hemos de señalar que habia acompañado a Miguel Fleta en sus actuaciones por toda Europa. En Colombia es citada igualmente como magnífica acompañante de Luis Macía, a quien acompañó al piano en varias ocasiones; entre ellas en unos programas de radio en los que fueron interpretadas "Las siete canciones populares de Manuel de Falla».

Además de las composiciones ya citadas, de las que es autora, María Rodrigo estrena con la Banda Municipal de Bogotá un pasodoble de una zarzuela suya: "La capa española», instrumentada para banda por Daniel Prat (también exiliado en Colombia y padre del ex-senador y Presidente del Ateneo de Madrid: José Prat).

\footnotetext{
${ }^{6}$ Véase Socarras, F., La Escuela Normal Superior: Bogotá, edición del autor. Obra en la que aparece detalle norminal de egresados y su encuadre profesional actual.

7 Mencionemos entre los exiliados españoles a: Pablo Vila, Luis de Zulueta, Pedro Urbano González de la Calle. José M. ${ }^{a}$ Ots Capdequí, José de Recasens, María Rodrigo, Francisco Vera, Manuel Usano, José Prat, Francisco de Abrisqueta, etc.
} 
Varios críticos musicales e importantísimos profesionales de la música en Colombia recuerdan su fabulosa interpretación al piano de su preciosa obra "La copla intrusa", en los conciertos celebrados en el Teatro Colón de Bogotá (el más importante de Colombia, aún hoy).

María Rodrigo pone música a la obra de Víctor Mallarino «El jardín de las imágenes"; obra de teatro de gran éxito que se estrenó y permaneció varios meses en el ya mencionado Teatro Colón.

Musicalizó igualmente la obra del mismo autor «A un año del recuerdo". Con Víctor Mallarino colaboró siempre estrechamente en arreglos, composiciones para sus obras o declamaciones, adaptaciones musicales para programas de radio, etc.

Tuvo que emigrar de nuevo alrededor de $1950^{\circ}$, instalándose definitivamente y hasta su fallecimiento en Puerto Rico, en donde se dedicó a la docencia, con toda probabilidad en la Universidad de Río Piedras (dato hasta el momento pendiente de confirmación).

Los trastornos ocasionados por la guerrra y el exilio fueron muy posiblemente una de las causas de las importantes alteraciones mentales que sufrió en sus últimos años.

En cuanto a Mercedes Rodrigo, hemos de decir que era madrileña como su hermana, y que nació el 12 de mayor de 1981. Llegó a Colombia en $1939^{\circ}$. En el momento de su exilio era ya psicóloga prestigiada en España, habiendo mantenido correspondencia con Freud ${ }^{10}$.

Había realizado estudios de especialización en Suiza. Terminados éstos dirigió en Madrid el Instituto Psicotécnico, fundado por Cesar de Madariaga. También prestó servicios de psicotecnia en el Instituto de Niños Superdotados, creado con idéntico impulso ${ }^{11}$.

Especialista, pues, en psicotecnia, fundó y dirigió el Servicio Psicotécnico de la Facultad de Medicina de la Universidad Nacional de Bogotá.

${ }^{8}$ Se cita sobre 1950, ya que, a pesar de que las fuentes orales mencionan 1953 , como la fecha más aproximada de su nueva emigración, los documentos consulares afirman: «El 12 de noviembre de 1949 se le expidió pasaporte a Estados Unidos, Honduras, Nicaragua, El Salvador y Costa Rica". A su hermana Mercedes se le había expedido el 21 de abril de 1949 pasaporte para Estados Unidos y Cuba.

${ }^{9}$ En su ficha consular se cita exactamente 2-8-1939.

10 Véase, LLORENS, V., "La emigración republicana de 1939 ", en la obra colectiva EI exilio español de 1939, dirigida por José Luis Abellan. Taurus 1976, Tomo I, pág. 175.

"A través de este organismo se llevaban a cabo exámenes y pruebas psicotécnicas a niños de todas las provincias españolas, y se les ofrecian estudios especiales en Madrid. 
Su importantísima labor en este campo, tan novedoso en la Colombia de 1939, y su larga experiencia, hizo que fuera llamada por el Ministerio de Educación colombiano para el que llevó a cabo, por primera vez en el país, un trabajo de orientación profesional con los alumnos del último curso de bachillerato, a fin de asesorarles con respecto a su elección de los estudios universitarios.

Mediante aplicación de tests y pruebas psicotécnicas, llevó a cabo su trabajo, demostrando una dedicación y entusiasmo propios de una profesional convencida, aplicada, consciente y responsable; ganándose asi un gran prestigio.

Trabajó también como profesora en la Universidad Nacional, para la que llevó a cabo un importantísimo y delicado trabajo y en el que demostró la honradez y profesionalidad más absolutas. Trabajo que fue motivo fundamental, con toda certeza, de su segundo y, por tanto doblemente penoso, exilio.

Mercedes Rodrigo Bellido fue encargada de llevar a cabo la selección para la entrada de alumnos en la Universidad Nacional. Se pretendia aplicar las nuevas técnicas y la gran experiencia de esta mujer prestigiosa, para acabar con las añejas arbitrariedades con las que se venía resolviendo el acceso a la Universidad estatal. Este trabajo la hizo enormemente impopular, aunque apoyada firmemente por el Catedrático de Fisiología, Rector por algún tiempo de la Facultad de Medicina, Dr. Ezguerra, hombre formado en Paris de mente abierta, y que supuso su mayor baluarte.

Mercedes Rodrigo emprendió la aplicación de pruebas psicotécnicas en esta selección, de la que parece ser la única responsable. La selección era problemática, las escasas plazas contrastaban con el gran número de candidatos. Bogotá apenas contaba en el momento con dos universidades estatales, frente a un número elevado de universidades privadas, siempre de unos costos muy superiores. Su honradez y profesionalidad, se vieron enfrentadas al interés y los privilegios de un sector de la población que nunca vio con buenos ojos a los republicanos españoles. En todo caso, los no favorecidos buscaron la culpabilidad en una extranjera que llevaba a cabo las pruebas de ingreso.

Según fuentes orales multitud de veces repetidas, el acoso llegó a ser considerable; incluso en la prensa se llegó a publicar, que una "roja» española estaba haciendo la selección para la entrada en la Universidad Nacional, favoreciendo asi la admisión de comunistas. 
"Era el año de 1947. En la Universidad Nacional "cazadores de brujas" resucitaron su trasnochada y sucia campaña contra los "rojos españoles" de los años de la II Guerra Mundial. Y volvimos a ver con sonrojo repetir por segunda vez en nuestro suelo patrio la consigna: "Colombia no necesita de sabios". En esas insoportables condiciones hubo de continuar el duro e interminable peregrinaje la República Española" ${ }^{12}$.

En abril de $1949{ }^{13}$ Mercedes Rodrigo marchó para Puerto Rico en donde trabajó para la Universidad de Río Piedras.

Las hermanas Rodrigo crearon en Bogotá el Instituto García Madrid para niños anormales. Este funcionó entre seis y ocho años. De él formarian parte como personal docente varios jóvenes exiliados españoles: José Garcia Madrid (llegado a Colombia con las hermanas Rodrigo, con las que convivió todo el tiempo de su permanencia en el país, y con ellas marchó a Puerto Rico), Asunción Madariaga ${ }^{14}$, Carmen Mayoral ${ }^{15}$, etc.

Maria y Mercedes Rodrigo Bellido se asentaron en Puerto Rico, en donde convivieron muy estrechamente con Juan Ramón Jiménez y del que llegaron a ocuparse en los últimos años de su vida.

MANUELA MANZANARES. Arabista, casada con José Francisco Cirre. La carencia de hijos de este matrimonio ya ha sido mencionada al hablar de las dificultades surgidas con la falta de fuentes orales directas.

Encontró, Manuela Manzanares, puesto como funcionaria en la Biblioteca Nacional.

Colaboró en la edición de Cartas de su archivo, recibidas por Rufino José Cuervo ( 5 tomos). No se menciona en esta obra su colaboración; pero este trabajo realizado por ella, si está en la memoria de un contemporáneo muy directo del Instituto Caro y Cuervo de Bogotá, al que entrevisté en esta ciudad en noviembre de 1988.

De su inquietud intelectual, su preparación polifacética y su amplia cultura nos hablan sus publicaciones conservadas en la Hemeroteca "Luis López de Mesa» de Bogotá, en la que encontramos trabajos en La

12 Osorio Osma, R., obra citada.

${ }^{13}$ Fecha consular de expedición de pasaporte.

${ }^{14}$ Hija del también exiliado en Colombia Cesar de Madariaga.

${ }^{15}$ Hija del Dr. Pedro Mayoral Carpintero, que llevó a cabo interesantísima campaña contra la Bartonelosis en la zona de Pasto. 
Revista de Indias, en la Revista de la Universidad de Antioquia, etc., sobre temas tan diversos como: Doña Gertrudis Gómez de Avellaneda, Rufino J. Cuervo y sus amigos, Quevedo, etc.

Manuela Manzanares, junto con su esposo, José Francisco Cirre, emigraron a Estados Unidos en donde trabajaron como profesores para la Wayne University de Detroit.

Con respecto a la motivación que pudo ocasionar esta nueva emigración, han sido mencionadas varias por fuentes orales de "segunda mano"; entre ellas, la más convincente, parece ser la economica. La enseñanza, siempre deficientemente retribuida, era en estos años en Colombia mucho menos rentable de lo que a título comparativo pueda serlo hoy. Francisco Cirre sólo consiguió trabajo en la Escuela Normal Superior; y el desempeño de Manuela Manzanares como funcionaria en la Biblioteca Nacional no parecía ofrecer un futuro económico más alagüeño. Quizás por ello el matrimonio Cirre-Manzanares se vio abocado a volver a emigrar de nuevo, esta vez a Estados Unidos. Los datos consulares archivados en la Embajada de España sobre ellos son nulos; por lo que suponemos su partida, alrededor del año cincuenta; siempre en base a relatos orales de varias fuentes indirectas y por tanto inconcretas.

M. ${ }^{a}$ ROSA MALLOL PIBERNAT. Nació en Barcelona en 1920. Realizó sus estudios de bachillerato en esta ciudad. Al concluirlos ingresó en el Taller Escuela de Pintura y Escultura de la Generalidad de Cataluña en Tarragona, que estaba dirigido en la parte escultórica por Juan Reboul y en la parte pictórica por su padre, el pintor Ignacio Mallol. M. ${ }^{a}$ Rosa cursó la especialidad de Escultura.

Ignacio Mallol e hijos, cuando el frente de Aragón estaba muy cerca, se trasladaron a vivir a Gerona; casi junto a la frontera. A la caída de Barcelona, pasaron a Francia y se instalaron cerca de París, en Boisie de la Rivière, hasta su partida a Colombia. En Barranquilla hacia varios años que estaba establecido su hermano Carlos ${ }^{16}$ con una compañía exportadora de cueros a España.

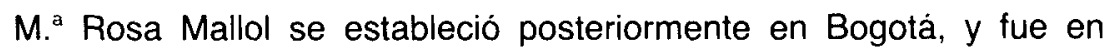
esta ciudad donde llevó a cabo sus estudios de Antropología, obteniendo

${ }^{16}$ Carlos Mallol fue Cónsul español del Gobierno de Franco en Barranquilla. 
su título en el Instituto Colombiano de Antropología, dirigido por Paul Rivet.

Contrajo matrimonio en Bogotá con el también exiliado republicano José de Recasens Tuset ${ }^{17}$.

Además de las labores familiares, $M{ }^{a}{ }^{a}$ Rosa Mallol llevó a cabo trabajos esporádicos de escultura, siempre asociados a proyectos arquitectónicos dirigidos por su esposo. Así esculpió un bajorrelieve para el Hotel Granada de Bogotá (hoy desaparecido), esculturas para jardines, etc. Este trabajo nunca fue tomado por ella como una profesión exclusiva.

En cambio si, trabajó en la investigación antropológica: viajó en comisión de estudios y residió unos meses en la Guajira, a fin de reunir material. También realizó investigaciones en la región del sur de Colombia, en la zona de Putumayo, y en otras zonas de la geografía colombiana; según se desprende de sus publicaciones.

En su bibliografía encontramos algunos trabajos individuales, otros en colaboración con su esposo, que nos hablan de la importancia de sus investigaciones en este campo. Citemos.

"Cuatro representaciones de la imágen alucinatorias originadas por la toma de Yagé", Revista Colombiana de Folklore. Segunda época. Vol. III, n. 8. Bogotá, págs. 59-78. Fotografías BICAN.

En este trabajo María Rosa Maliol llevó a cabo un análisis sicológicosicoanalítico de la información recogida de un indigena Siona en 1963 acerca de sus primeras cuatro tomas de yagé. El método de investivación consistió en solicitar al informante, quien se encontraba en Bogotá, primero un relato y luego una extensa serie de dibujos sobre cada una de las cuatro tomas; después de comparar los relatos con los dibujos, se procedió a precisar la información mediante un nuevo y último ciclo de preguntas. La autora consideraba que este procedimiento permitía la expresión de instancias que de otra manera pasarian desapercibidas.

Otros trabajos realizados en colaboración con su esposo fueron:

17 Alumno del taller Escuela de la Generalidad de Cataluña en Tarragona, en la especialidad de Pintura, José de Recasens habia cursado además Arquitectura y Filosofia en la Universidad de Barcelona. En Colombia desarrolló un polifacético e intenso trabajo, digno de un estudio monográfico; abarcando múltiples campos: periodista, escritor, profesor en la Escuela Normal Superior y en varias universidades, antropólogo, arquitecto; trabajó en programaciones educativas y científicas en radio y televisión, etc. Siendo en la actualidad Decano de la Facultad de Comunicación Social de la Universidad Externa de Colombia. 
"Estudio comparativo de vivienda en Buenaventura y Puerto Colombia", Revista Colombiana de Antropología. Vol. XII. Bogotá (1963), págs. 293-328, 4 dibujos.

Los autores centraron su investigación en 100 familias de Buenaventura y 25 de Puerto Colombia, estudiando el promedio de metros cuadrados por persona, las condiciones específicas de la vivienda, los servicios y las necesidades sentidas por las personas en lo relacionado con la vivienda, además de las caracteristicas generales de habitación en lo económico, funcional y tecnológico.

"Dibujo infantil y personalidad cultural en la isla de San Andrés», Revista Colombiana de Antropologia. Vol. XIII. Bogotá (1964-1965), págs. 183-214, con fotografias de dibujos infantil. BICAN.

Aquí se analizan las correspondencias entre la representación del tema de la familia y su estructura real o encubierta, en la isla de San Andrés. Concebido como complemento a una investigación socioeconómica de la isla, este trabajo permitió a sus autores afirmar la validez del dibujo infantil como técnica de investigación útil en la verificación de datos obtenidos por métodos antropológicos tradicionales.

Por último:

"Contribución al conocimiento del Cacique-Curaca entre los Siona", Revista Colombiana de Antropología. Vol. XIII. Bogotá (1964-1965), págs. 91-145. BICAN.

En este trabajo el matrimonio Recasens estudió el significado y la función del rol cacique-curaca entre los indígenas Siona del río Putumayo en la intendencia del Putumayo, aplicando a un informante una técnica de investigación consistente en recoger su relato sobre ese tema, a continuación le solicitaban que lo representara gráficamente; confrontando, por último, relato y dibujo ${ }^{18}$.

También se exilió en Colombia GENOVEVA PONS ROTGER, que nació en la isla de Menorca en 1912. Muy pronto sus padres, artesanos, emigraron a París, donde el estallido de la primera guerra europea les obligó a regresar a España.

is Bibliografía anotada y directorio de antropologos colombianos. Bogotá, Sociedad antropológica de Colombia, julio 1979. 
La familia Pons se instaló en Valencia, por lo que Genoveva, que contaba poco más de año y medio, creció y realizó sus estudios en esta capital, considerándose a sí misma siempre como valenciana.

Ingresó en la Escuela Normal de Magisterio. Tras las finalización de estos estudios y las oposiciones pasó a ser Maestra en la Escuela de Liria. También cursó estudios en la Escuela de Puericultura de la capital valenciana.

Durante su tiempo libre dio clases nocturnas para adultos, en un local que le facilitaron gratuitamente. Fundó una biblioteca circulante, y durante el verano trabajó con niños en colonias escolares de vacaciones.

Nada más terminar la guerra civil, le fueron entregados unos documentos para solicitar su rehabilitación como Maestra Nacional. Pero el 31 de mayo de 1939 recibió un oficio, en él se le comunicaba haber sido suspendida de empleo y sueldo.

Genoveva Pons afirma que "alguien debió utilizar en su beneficio mi nombre, alguien o algunos vinculados al magisterio de Liria, denunciantes eficientes cuyo malévolo testimonio produjo como resultado además de mi destitución que les dejaba vacante un puesto apetecible, toda una serie de hechos..." ${ }^{19}$, que la llevaron a prisión el 17 de julio de 1939, de donde salió el 6 de mayo de 1942.

En la fecha de su puesta en libertad, su padre Antonio Pons Petrus, que había sido encarcelado simultáneamente con ella, continuaba en el Penal de San Miguel de los Reyes. Hasta después de dos años, en 1944, no consiguió su libertad; aunque falleció en ese mismo año, víctima de un organismo sin reservas, a causa del largo cautiverio.

En 1947 contrajo matrimonio. Su esposo habia pasado por pruebas similares a las suyas ${ }^{20}$. Uniendo sus aportaciones se instalan en un piso de una céntrica avenida, creyendo que habian terminado sus sinsabores.

19 Pons Rotger, Genoveva, Tres años de antaño. Publicación de edición limitada a 100 ejemplares, llevada a cabo en Bogotá en 1984; en la que a manera de diario, la protagonista relata hechos y sentimientos.

20 PEREZ, José Alfonso. Nacido en Rocafor (Valencia) en 1911, de profesićn ebanista. Afiliado al PSOE. Sufrió 5 años de presidio en la Cárcel Modelo de Valencia. En 1944 fue puesto en libertad. 
En España, no obstante, continuaban las persecuciones. La intimidad de su hogar era violada a cualquier hora a causa de redadas en las que se veían incluidos.

En mayo de 1952, su marido junto con otros amigos fueron llevados a los calabozos de la Dirección General de Seguridad, y aunque permanecieron pocos dias, acabaron por pensar que nunca les dejarían tranquilos.

Genoveva Pons escribió una angustiosa carta a Washington y unos amigos generosos la pusieron en contacto con los dueños norteamericanos de un colegio privado de Bogotá.

Un contacto de trabajo que le fue facilitado, le abrió las puertas de Colombia.

Llevó consigo tan sólo su capacidad de trabajo, la esperanza de ser bien acogida y el móvil de poder conseguir que su familia se reuniese con ella en tierras de libertad, para organizar una nueva vida con dignidad y respeto.

A los ocho meses de su llegada a Bogotá, vinieron su esposo y su madre, reclamados por ella.

Genoveva Pons trabajó cinco años en la enseñanza privada en la capital colombiana, llevando simultáneamente la contabilidad de algunas empresas, y dando clases particulares.

Junto con su esposo, José Alfonso Pérez, de profesión ebanista, creó una pequeña industria: "Muebles Rocafort».

Genoveva simultaneó su labor docente con el trabajo de contabilidad y administración en la industria familiar. Ocupación, esta última, a la que se dedicó de manera exclusiva a partir de 1958, junto con el trabajo familiar y el cuidado de su hija.

En 1973, un desgraciado accidente la privó de la compañía de su esposo; en su temor por la pérdida de la razón, se vinculó a la Cruz Roja; y «tratando de ayudar a los demás, me ayudé a mí misma»-dice Genoveva Pons-.

En febrero de 1979, a los cuarenta años de haber sido despojada de su plaza de Maestra, fue reincorporada y regresó a España para trabajar en su profesión.

Genoveva Pons Rotger, jubilada, reside actualmente en Bogotá (Colombia). 
LUCÍA GARCíA VILLAFRANCA. Nació en Madrid el 25 de abril de 1900. Habia estudiado en París con las hermanas del Sagrado Corazón; cursando posteriormente estudios de música en Londres, que finalizaria en el Conservatorio de Madrid, en la especialidad de piano. Su amplia cultura la llevó a colaborar con el gobierno republicano realizando trabajos de traducción, fundamentalmente durante la guerra. Lucia García dominaba perfectamente inglés, francés, italiano y parcialmente alemán.

Casó con Benito Velo Temes, a quien conoció en Madrid cuando este cursaba los estudios de Ingeniería Civil.

Al comenzar la guerra, ambos, junto con su hija Maria Luz, se encontraban en Cáceres, donde a Benito Velo le ha sido encomendado por el gobierno republicano, un trabajo de ingeniería. A la llegada de las tropas de Franco a esta ciudad, le fue solicitada una firma de adhesión al alzamiento del General Franco. Al negarse a ello el Sr. Velo, aduciendo que él obedeció órdenes de trabajo del gobierno de la República, legalmente constituido, y que no reconocia ningún otro; fue encarcelado.

Benito Velo, era natural de Vigo. En esta ciudad su padre ejercía desde tiempo como notario, alcanzando su familia una destacada posición en la ciudad. Por intervención suya, fue puesto en libertad.

La familia, con temor ante la situación, viajó a Vigo; y desde allí partieron en un barco inglés a San Juan de Luz. Su idea era ir a trabajar a Inglaterra.

En París tomaron contacto con el embajador español Luis Araquistain. El y su esposa eran amigos desde tiempo atrás de los esposos Velo. ante los temores de éstos, el Sr. Araquistain logró tranquilizarlos, convenciéndoles de que en aquellos momentos difíciles un ingeniero como él podía ser muy valioso para la República.

Conscientes de ello, la familia Velo, regresó a España. Llegaron a Valencia y después se instalaron en Madrid. Lucía G. Villafranca comenzó a colaborar con el Ministerio de Relaciones Exteriores. (La había unido desde la infancia una estrecha amistad con la esposa de Álvarez del Vayo.) Se encargaba del trabajo de traducciones.

Posteriormente se trasladaron a Barcelona. A Benito Velo le nombraron Capitán de Ingenieros. En ur.o de sus trabajos profesionales, llevados a cabo en servicio de la República en la zona de Cataluña, fue dado por desaparecido.

Lucia Garcia permaneció con su hija en Barcelona esperando recibir noticias de su esposo. 
Cuando la situación era ya insostenible, por encontrarse los ejércitos de Franco a las puertas de Barcelona; recurrió a Juan Negrín (hijo); éste les proporcionó los medios para llegar a un pueblo cerca de la frontera francesa. Por la noche, un camión carpado en el que viajaban los funcionarios, las secretarias y el personal del Ministerio, vino a recogerlas.

Instaladas en la iglesia, habilitada para albergue, perdidos los contactos, esperaban sin ningún resultado. Decidieron trasladarse a pie a otro pueblo (¿Figueras?), en donde se encontraba el ejército republicano. Era imposible poder salir de alli y pasar la frontera, todos estaban desconectados, la situación era caótica. Lucía García contactó con una corresponsal francesa, Marta Wisman. En el coche de ésta, la madre en el maletero y la hija de nueve años y medio, bajo el asiento delantero, pasaron la frontera.

Una vez en Paris, y por medio de la Cruz Roja Internacional, Lucia Garcia logró comunicarse con sus hermanas, que, casadas con ciudadanos británicos, vivian desde hacía tiempo en el Reino Unido.

Se instalaron con su familia en Monk Seapton. Lucia G. Villafranca se dedicó a buscar a su esposo por todos los medios a su alcance. Visitó el Ministerio de Relaciones Internacionales, indagó a traves de la Cruz Roja Internacional con un tesón y un empuje propios de su carácter enérgico y voluntarioso, a pesar de lo cual desfalleció por algún tiempo y su mente pareció flaquear. Después de un año de búsqueda, logró averiguar que su esposo estaba en un campo de concentración en el sur de Francia en unas circunstancias infrahumanas. No escatimó esfuerzos para conseguir la liberación, que logró por medio de la Cruz Roja Internacional.

Ya en Londres, Benito Velo, viendo que la situación en Europa no se avecinaba estable, decidió marchar con su familia a Colombia. Alli su hermana menor estaba casada con Alfredo Gómez Venegas, vinculado al Gobierno de Eduardo Santos. Por intervención directa de éste, como en tantísimos casos de los españoles que se exiliaron en Colombia, les fue ofrecida la Visa para entrar en el país. Pero se planteó un problema, ellos no tenian pasaporte. El Foreing Office en Londres les expedió un pasaporte-carta; documento que les permitió cumplir la legalidad y llegar a Colombia.

En el Orduña atravesaron el Atlántico y llegaron a Bogotá el 6 de mayo de 1940. Después de haberse instalado en esta ciudad, Benito Velo pareció tener un buen futuro de trabajo. Había pocos ingenieros en el pais, apenas los hermanos García Reyes, también exiliados republicanos, iban a hacerle la competencia. Pero Benito Velo comenzó a mostrar 
alteraciones de conducta producidas por los problemas mentales ocasionados por los traumas sufridos. Su retraimiento e inhibición llegaron a hacerse patológicos. Continuamente se sentía acosado y perseguido por unos enemigos no presentes en su realidad física, tan solo en su realidad mental.

Lucía García debió tomar las riendas económicas de la familia. Su amplia cultura y polifacética preparación la permitieron entrar en el mundo de la enseñanza.

En 1941 ingresó como profesora en el Liceo Francés «Luis Pasteur». Se trataba de un colegio internacional, dependiente del Gobierno galo, que mediante un convenio educativo impartía enseñanza bilingüe en Bogotá.

Madame Velo, como a partir de este momento sería conocida, incluso en la colonia española, impartió enseñanza globalizada en tercero, cuarto y quinto de educación elemental; excepto religión, historia y geografia de Colombia, que según el convenio educativo debían de ser impartidas por profesores colombianos.

Lucia G. Villafranca se dedicó a su nueva profesión con el ímpetu, la energía y el empeño que la caracterizaba. Se aplicó a la educación tan responsablemente, que aún hoy sus alumnos y compañeros de trabajo la recuerdan con entusiasmo en sus métodos motivadores, su carácter amable y su gran personalidad.

Cuando los alemanes invadieron Francia, se cortó la subvención que venía sustentando económicamente al Colegio Luis Pasteur de Bogotá. Éste no contaba con ningún tipo de medios para poder mantenerse. El director Monsieur Lagnelle, reuniendo al Claustro le explicó la situación por la que atravesaba el colegio. Madame Velo decidió solidarizarse y continuar trabajando sin sueldo, hasta que la situación se regularizase.

Después de transcurridos estos años duros de la guerra, Lucía Garcia continuó igualmente su intensa labor docente en el Colegio Francés hasta su jubilación, en total casi 24 años.

La labor docente de Madame Velo, y su solidaridad en los malos momentos, la hicieron merecedora de "La Palma Académica», condecoración instituida en la época napoleónica, que el Gobierno francés la concedió en 1955, reconociendo su trabajo intenso y abnegado y su solidaridad.

Después de su jubilación en 1965 y por decisión familiar, Lucía G. Villafranca fundó un centro de educación preescolar bilingüe, que se 
llamó “Kinder francés Sta. Genoveva». Ella fue, junto con su hija y su esposo, la principal promotora y la directora del mismo.

Llevó a cabo un convenio con el Colegio Francés "Luis Pasteur» por el que se comprometia a establecer cursos de primero, segundo y tercero de "Kinder" en educación bilingüe. El liceo, siempre con plazas insuficientes para atender las demandas, se comprometió a recibir a los alumnos al finalizar el último curso, según fuera teniendo plazas, y a enviarle, en los otros cursos de preescolar a los alumnos que no pudiera admitir por falta de cupo.

Con un impetu y un trabajo tenaz, que caracterizó toda su vida, luchando contra las adversidades económicas; el centro de educación preescolar se transformó en "Colegio Francés Santa Genoveva", llegando a impartir hasta quinto curso de ensenanza elemental; aprobado y reconocido por el Gobierno colombiano.

En este colegio Lucía García Villafranca siguió trabajando hasta su fallecimiento en Bogotá el 1 de agosto de 1971.

\section{EPÍLOGO}

El propio lector puede contrastar las historias de vida presentadas en este trabajo. Hay una diferencia cuantitativa y cualitativa importante en ellas.

Las fuentes orales condicionan, en todos los casos, estas diferencias.

En las ocasiones en las que nos enfrentamos con la carencia de fuentes orales directas, son detallados los datos fríos del trabajo llevado a cabo por estos protagonistas, a los que por referencias indirectas de otras fuentes se ha podido tener acceso. Por ejemplo, en el caso de la hermana Rodrigo, se ha podido consultar la biblioteca del Conservatorio Superior de Música, o del Departamento de Psicología de la Universidad Nacional; siempre partiendo de la base del relato de una fuente oral que recuerda su trabajo en estos organismos; recuerdos casi siempre, vagos o inconcretos, que se intentan fundamentar o contrastar con la posible documentación existente en los archivos de las instituciones citadas. 
A veces esta documentación se encuentra, y en este caso, ella suele llevarnos a concretar la información y ampliar la misma. En otros casos, como en el de María Rodrigo, la documentación que fue encontrada en la biblioteca del Conservatorio de la Universidad Nacional, se redujo a un programa de curso en el que aparecia como profesora.

El detalle y conocimiento de algunas de sus obras se basan en fuentes orales diferentes, que se han apoyado y confirmado unas a otras. José Prat, exiliado en Colombia, entrevistado en varias ocasiones, recuerda obras de María Rodrigo, también recordadas por músicos y musicólogos contemporáneos, quienes tan solo pudieron aportar el título de una o varias obras que escucharon en algún concierto ofrecido por la protagonista.

Tanto en el caso de las hermanas Rodrigo, como en el de Manuela Manzanares, desconocemos los datos de las vivencias personales, de las circunstancias que motivaron la elección de Colombia para la ubicación de su exilio, etc., aunque podamos tener alguna referencia del motivo que les llevó a abandonar el país nuevamente, después de varios años; motivación siempre sumida en el ámbito de la posibilidad.

No es el caso de las historias de vida de M. ${ }^{\text {a }}$ Rosa Mallol, Genoveva Pons y Lucia Garcia Villafranca, cuyas realidades aparecen humanizadas, argumentadas y detalladas, dado que la existencia de una fuente oral directa nos facilita de una manera fundamental la reconstrucción de sus circunstancias personales, su trabajo y su vida antes y después del exilio. Por tanto, en estos casos tenemos, a través de la fuente oral, acceso a mucha más información que en los anteriores. Por una parte, el relato nos facilita una información que, de lo contrario, sería totalmente imposible de conocer con tanta profundidad, detalle y exactitud; y, por otra, nos facilita el acceso a las fuentes documentales complementarias del testimonio oral. 